\title{
Association between masticatory movement and oral and physical function in healthy older women
}

\author{
Yoko Kato a , Takeshi Kikutani ${ }^{\text {a,b }}{ }^{*}$, Keiichiro Sagawa ${ }^{\text {b }}$, Fumiyo Tamura ${ }^{\text {b }}$ \\ a Division of Clinical Oral Rehabilitation, The Nippon Dental University, Graduate School of Life Dentistry at Tokyo, Japan \\ ${ }^{b}$ Division of Rehabilitation for Speech and Swallowing Disorders, The Nippon Dental University, Tama Oral Rehabilitation Clinic, Tokyo, Japan
}

\begin{abstract}
Purpose: This study examined the association between masticatory movement and oral and physical function in healthy older women using clinical assessments considering central motor control.

Methods: A total of 107 independent older women (mean age, $74.37 \pm 4.46$ years; age range, $66-84$ years) living in the community participated in this cross-sectional study. The subjects selected were those aged 65 years or older with at least 28 teeth and without oral dysfunction, temporomandibular joint (TMJ) disease, cerebrovascular disease, or neuromuscular disease. The following items of oral and physical function were measured: masticatory path pattern, masticatory performance, oral diadochokinesis (ODK), tongue pressure, single-leg stance with eyes open (SLS), stepping test, and grip strength. Logistic regression analysis adjusting for age was performed to investigate the association between masticatory movement and other items.

Results: In total, $30.8 \%$ of subjects were classified into the abnormal group regarding masticatory path pattern, having a significantly lower value than that of the normal group in masticatory performance (unadjusted $p=0.021$ ). After adjusting for age, the masticatory path pattern was significantly associated with masticatory performance $(p=0.032)$; ODK $/ \mathrm{pa} /(p<$ $0.001), / \mathrm{ta} /(p=0.022)$, and $/ \mathrm{ka} /(p=0.016) ;$ and stepping test $(p=0.018)$. Tongue pressure, SLS, and grip strength were not significantly associated with masticatory path pattern.

Conclusion: Masticatory movement in older women was associated with masticatory performance, tongue and lip motor skills, and physical agility, which might be influenced by central motor control.
\end{abstract}

Keywords: Older women, Masticatory path pattern, Motor control, Oral function, Physical function

\section{Introduction}

Masticatory function has been reported to be associated with peripheral oral conditions, such as tooth number, occlusal force, and saliva flow [1,2]. Hence, the traditional treatment for masticatory problems mainly addresses the peripheral organs of the oral cavity, such as prosthetic, conservative, and periodontal treatments. However, oral hypofunction in the older population has been highlighted as a growing problem [3]. This requires comprehensive assessment and treatment, focusing not only on the organic factors of the oral cavity, but also functional factors.

Various studies have examined the association between oral function and physical function from the perspective of long-term care prevention [4]. Many reports have focused on oral conditions, such as the number of teeth and occlusal support [5-7]. In recent years, several reports have highlighted the muscle strength of oral

DOI: https://doi.org/10.2186/jpr.JPR_D_20_00285

*Corresponding author: Division of Rehabilitation for Speech and Swallowing Disorders, The Nippon Dental University Tama Oral Rehabilitation Clinic, 4-44-19 Higashicho, Koganei-city, Tokyo, 184-0011, Japan.

E-mail address: kikutani@tky.ndu.ac.jp (T. Kikutani).

Copyright: @ 2021 Japan Prosthodontic Society. All rights reserved. and physical functions, such as tongue pressure and grip strength [8], occlusal force and grip strength [9], and occlusal force and lower limb muscle strength [10]. However, only a few reports have examined the association between oral and physical motor control, such as tongue motor skill and body balance [11], and chewing rate and walking rate [12].

Regarding masticatory movement, an important element of masticatory function, various evaluation methods have been reported $[13,14]$. In Japan, Kobayashi's group presented a method to evaluate the masticatory path and has made progress in its clinical application [15]. However, since previous studies have mainly focused on young people, little is known about older people. Furthermore, abnormal masticatory movement has been considered mainly to be due to peripheral feedback, such as periodontal ligaments [16], occlusion [14,17], and the effect of prosthetic treatment [18].

Masticatory movement is controlled not only by peripheral feedback but also by higher centers [19]. Neuroimaging studies have shown that masticatory performance in older people is associated with individual structural and functional differences in the brain [20]. In the cerebellar anterior lobes, which are predominantly involved in motor control, significant age-related losses in volume and cell proportion have been shown [21]. A recent review suggests that 
morphological and functional age differences in the cerebellum affect motor and cognitive performance [22]. For these reasons, agerelated changes in the central nervous system may contribute to individual differences in motor control, leading to abnormal masticatory movement and poor masticatory performance. If individual differences in motor control originate from the central nervous system, the influence should be seen not only in the oral region but also in other parts of the body.

This study examined the association between masticatory movement and oral and physical function in healthy older women using clinical assessments considering central motor control.

\section{Materials and methods}

\subsection{Participants}

This cross-sectional study was based on data from 1355 participants in physical fitness sessions held for independent older people living in Kyoto City, Japan. The eligibility criteria were age 65 years or older, female sex, with at least 28 teeth excluding those with severe mobility (Miller's index class 3 [23]) or residual root teeth. To focus on central motor control in healthy older women, the study excluded as far as possible organic factors in the oral cavity or disease factors that might cause abnormal masticatory movement. Therefore, those with oral dysfunction or temporomandibular joint (TMJ) disease were excluded following interview and palpation. Those with major diseases that could cause movement disorders, such as cerebrovascular or neuromuscular diseases, were also excluded. Considering the sex differences in physical performance [24,25], only women were included in this study.

Written informed consent was obtained from each participant after explaining the purpose and methods of the study. This study was approved by the Ethics Committee of The Nippon Dental University, School of Life and Dentistry at Tokyo (approval number: NDUT2019-02).

The sample size was calculated using $G^{*}$ Power 3.1.9.2 Statistical Power Analyses (Heinrich-Heine-Universität Düsseldorf, Düsseldorf, Germany) with an alpha error of 0.05 , a power of 0.8 , and a medium effect size [26]. It was estimated that more than 106 subjects were required for this study.

\subsection{Evaluations}

As a general characteristic of the subjects, body height and weight were measured to calculate body mass index (BMI) using the formula: body weight $(\mathrm{kg}) /$ height $(\mathrm{m})^{2}$. Oral function and physical function were evaluated using the following items in terms of motor control [27-29] and muscle strength. To assess oral function, masticatory path pattern as an indicator of masticatory movement, masticatory performance as an indicator of masticatory function, a syllable repetition task [27], oral diadochokinesis (ODK) as an indicator of tongue and lip motor skill, and tongue pressure as an indicator of muscle strength were evaluated. To assess physical function, singleleg stance with eyes open (SLS) as an indicator of balance [28], the stepping test as an indicator of agility [29], and grip strength as an indicator of muscle strength were evaluated. Physical function was measured according to the method of Kimura et al. [30], which was devised to be suitable and safe for adults aged $\geq 60$ years who had not exercised for a long time.

\subsubsection{Masticatory path pattern}

According to the method of Kobayashi et al. [15], the subjects were asked to chew gummy jelly (GLUCOLUMN, GC Corporation, Tokyo, Japan) on their habitual chewing side for 20 seconds. Mandibular movement was recorded three-dimensionally using a Motion VISI-TRAINER V-1 (GC Corporation). Of the recorded waveforms, the fifth to fourteenth cycles viewed from the frontal plane were superimposed by the dedicated software to display patterns. The displayed pattern was divided into patterns I-VII, according to a previous study [15]. The subjects with patterns I or III, which were considered healthy patterns, were classified into the normal group. Those who showed patterns other than patterns I or III were classified into the abnormal group.

\subsubsection{Masticatory performance}

Glucose extraction was measured as a parameter for masticatory performance according to the method described by Shiga et al. [31]. The subjects were asked to sit and chew a glucose-containing gummy jelly (GLUCOLUMN, GC Corporation) on their habitual chewing side for $20 \mathrm{~s}$. After chewing, the subjects were asked to put $10 \mathrm{~mL}$ of distilled water into their mouths and then spit out all the chewed gummy jelly, saliva, and water into a filtered cup. The glucose concentration in the filtrate was measured using a glucose measuring device (GC Corporation).

\subsubsection{Oral diadochokinesis}

The subjects were asked to pronounce the monosyllables, /pa/, /ta/, and /ka/, for 5 seconds as fast as possible, according to a previous method [32]. The number of repetitions per second was calculated using a measurement device, the Kenko-Kun Handy (Takei Scientific Instruments Co., Ltd., Niigata, Japan).

\subsubsection{Tongue pressure}

Tongue pressure was measured using a tongue pressure measurement device (JM-TPM, JMS Co., Ltd., Hiroshima, Japan). Following the method of Hayashi et al. [33], the subjects were asked to press a balloon against the hard palate with maximum force for $2 \mathrm{~s}$. After measuring three times at 1-minute intervals, the peak value was recorded.

\subsubsection{Single-leg stance with eyes open}

Single-leg stance with eyes open was measured in 1/100 increments using a stopwatch. The subjects were asked to stand on their dominant leg with their hands on their hips and one foot approximately $5 \mathrm{~cm}$ off the floor. The measurement ended when the support leg shifted significantly, the hands stopped contacting the waist, any part of the body other than the support leg touched the floor, or when a maximum of $180 \mathrm{~s}$ was reached.

\subsubsection{Stepping Test}

Two lines were marked $30 \mathrm{~cm}$ apart at the foot of a chair. The subject was asked to sit on a chair with their legs easily movable. For the starting position, the subject grasped the seat with both hands to stabilize the upper body placed both feet inside the two lines. On cue, the subjects performed an opening and closing motion of both legs as fast as possible across the line for 20 seconds. The number of 


$\begin{aligned} & \text { Total participants in physical fitness sessions } \\ & (\mathrm{n}=1355)\end{aligned}$
$\begin{aligned} & \text { NOT ASSESSED FOR ELIGIBILITY } \\ & \text { Refused to participate }(\mathrm{n}=13)\end{aligned}$

Assessed for eligibility

$(\mathrm{n}=1342)$

\begin{tabular}{|l|l|}
$\begin{array}{l}\text { INELIGIBLE } \\
\text { Age }<65(\mathrm{n}=60) \\
\text { Male }(\mathrm{n}=299)\end{array}$ \\
$\begin{array}{l}\text { INELIGIBLE } \\
\text { Missing of oral status or function data }(\mathrm{n}=373) \\
\text { Teeth }<28(\mathrm{n}=452)\end{array}$ \\
$\begin{array}{l}\text { EXCLUDED } \\
\text { Oral dysfunction }(\mathrm{n}=12) \\
\text { Temporomandibular joint disease }(\mathrm{n}=23) \\
\text { Cerebrovascular or neuromuscular diseases }(\mathrm{n}=16)\end{array}$ \\
\hline Subjects included in the analysis \\
\hline $\mathrm{n}=107)$
\end{tabular}

Fig. 1. Flow chart of the study.

times both feet touched inside the two lines without stepping on the lines or dragging their feet was recorded.

\subsubsection{Grip strength}

Grip strength was measured using a digital dynamometer (TKK5401; Takei Scientific Instruments Co., Ltd., Niigata, Japan). The width of the dynamometer's grip was adjusted so that the second joint of the index finger was almost at a right angle. The subjects held the dynamometer in a standing position with their arms extended and did not touch any other part of their body. The subjects grasped their right hand and left hand once each with a full force. The larger measurement from the two sides was used for evaluation.

\subsection{Statistical analysis}

Statistical analysis of normal or abnormal masticatory path patterns and each measurement item was performed as follows. The mean or median values of each measurement item were compared using an independent sample $t$-test or Mann-Whitney $U$ test. Logistic regression analysis was performed, adjusting for age, to investigate associations between each item and masticatory path pattern. Missing values were replaced by mean values. The level of significance was set at $p<0.05$. All statistical analyses were performed using IBM SPSS Statistics for Windows, Version 26.0 (IBM Corp., Armonk, NY).

\section{Results}

A total of 107 older women (mean age $74.37 \pm 4.46$ years, age range 66-84 years) were included in the analysis (Fig. 1). The general characteristics of the subjects according to masticatory path pattern are shown in Table 1. The number (percentage) of participants with a given masticatory path pattern was as follows: pattern I, 52 (48.6\%); pattern II, 13 (12.1\%); pattern III, 22 (20.6\%); pattern IV, 4 (3.7\%); pattern V, 6 (5.6\%); pattern VI, 7 (6.5\%); and pattern VII, 3 (2.8\%). The normal group with Pattern I or III accounted for $69.2 \%$ of the total,
Table 1. General characteristics of the subjects by masticatory path pattern.

\begin{tabular}{lccc}
\hline & \multicolumn{2}{c}{ Masticatory path pattern } & \\
\cline { 2 - 3 } & Normal $(\mathrm{n}=74)$ & Abnormal $(\mathrm{n}=33)$ & Total $(\mathrm{n}=107)$ \\
& Mean (SD) & Mean (SD) & Mean (SD) \\
\hline Age $(\mathrm{y})$ & $74.12(4.64)$ & $74.94(4.02)$ & $74.37(4.46)$ \\
$\mathrm{BMI}\left(\mathrm{kg} / \mathrm{m}^{2}\right)$ & $21.08(2.47)$ & $20.63(2.04)$ & $20.94(2.35)$ \\
Number of teeth & $28.88(1.35)$ & $28.76(1.30)$ & $28.84(1.33)$ \\
\hline
\end{tabular}

BMI: body mass index, SD: standard deviation

whereas the abnormal group with a pattern other than Pattern I or III accounted for $30.8 \%$ of the total.

The associations between masticatory path patterns and each measurement item are shown in Table 2. The abnormal group had significantly lower values than those of the normal group in masticatory performance, ODK / $\mathrm{pa} /$ and /ta/, and stepping test, with a significant association before and after adjusting for age (masticatory performance, unadjusted $p$-value $=0.021$, adjusted $p$-value $=0.032$; ODK /pa/, unadjusted $p$-value $<0.001$, adjusted $p$-value $<0.001$; ODK $/$ ta/, unadjusted $p$-value $=0.038$, adjusted $p$-value $=0.022 ;$ stepping test, unadjusted $p$-value $=0.011$, adjusted $p$-value $=0.018)$. ODK $/ \mathrm{ka} /$ showed a significant association with masticatory path pattern after adjusting for age $(p=0.016)$. Tongue pressure, SLS, and grip strength were not significantly associated with normal or abnormal masticatory path patterns.

\section{Discussion}

The purpose of this study was to investigate the association between masticatory movement and oral and physical function using clinical assessments considering central motor control. The results indicated that some people had abnormal masticatory movements, even after excluding various peripheral and disease factors. In addition, abnormal masticatory movement was associated with tonguelip motor skill and physical agility, suggesting that it might be influenced by central motor control.

The percentage of healthy older women with abnormal masticatory path patterns was $30.8 \%$. We expected that the proportion of the people in the abnormal group would be higher among older people than among younger people, considering the influence of motor control in older people [20-22]. However, the proportion of the participants in the abnormal group in this study was approximately the same as that in a previous study in young adults [15]. In a previous study, the number of female participants was approximately half as small as that in the current study. In addition, measurements were taken on each chewing side, regardless of the habitual chewing side. Therefore, a simple comparison cannot be made. We suspect that if the number of participants was increased and only the habitual chewing side was measured, the proportion of healthy young people in the abnormal group would be much higher. In this study, the masticatory performance of the abnormal group was significantly lower than that of the normal group, and there was a significant association between masticatory movement and masticatory performance. These findings suggest that abnormal masticatory movements might contribute to poor masticatory performance.

Several reports [20-22,34,35] suggested that age-related changes in the brain and individual morphological and functional differ- 
Table 2. Associations between masticatory path pattern and each measurement item.

\begin{tabular}{|c|c|c|c|c|c|c|c|c|c|}
\hline & \multicolumn{4}{|c|}{ Masticatory path pattern } & \multirow{3}{*}{$\begin{array}{c}\text { Total }(n=107) \\
\text { Mean }(S D)\end{array}$} & \multirow{3}{*}{$\begin{array}{l}\text { Unadjusted } \\
p \text {-Value }{ }^{(1)}\end{array}$} & \multirow{3}{*}{$\begin{array}{c}\text { Adjusted } \\
\text { OR }\end{array}$} & \multirow[b]{3}{*}{$95 \% \mathrm{Cl}$} & \multirow[b]{3}{*}{$p$-Value $\mathrm{e}^{(2)}$} \\
\hline & \multicolumn{2}{|c|}{ Normal $(n=74)$} & \multicolumn{2}{|c|}{ Abnormal $(n=33)$} & & & & & \\
\hline & Mean (SD) & Median [IQR] & Mean (SD) & Median [IQR] & & & & & \\
\hline Age (y) & $74.12(4.64)$ & $74.00[70.00-78.00]$ & $74.94(4.02)$ & $74.00[72.00-77.50]$ & $74.37(4.46)$ & 0.333 & & & \\
\hline $\begin{array}{l}\text { Masticatory performance } \\
(\mathrm{mg} / \mathrm{dL})\end{array}$ & $203.36(44.88)$ & & $182.18(39.55)$ & & $196.83(44.22)$ & $0.021^{*}$ & 0.99 & $0.98-1.00$ & $0.032^{* * *}$ \\
\hline ODK /pa/ (times/sec) & $6.64(0.61)$ & $6.70[6.20-7.00]$ & $5.98(1.00)$ & $6.20[5.60-6.60]$ & $6.44(0.80)$ & $<0.001^{* *}$ & 0.31 & $0.17-0.60$ & $<0.001^{* * *}$ \\
\hline /ta/ (times/sec) & $6.67(0.65)$ & $6.60[6.20-7.00]$ & $6.30(0.77)$ & $6.40[5.80-6.80]$ & $6.56(0.71)$ & $0.038^{* *}$ & 0.48 & $0.25-0.90$ & $0.022^{* * *}$ \\
\hline /ka/ (times/sec) & $6.24(0.53)$ & $6.20[5.80-6.60]$ & $5.92(0.72)$ & $6.00[5.60-6.20]$ & $6.14(0.61)$ & 0.055 & 0.41 & $0.20-0.85$ & $0.016^{* * *}$ \\
\hline Tongue pressure $(\mathrm{kPa})$ & $33.06(6.72)$ & & $32.52(5.74)$ & & $32.89(6.41)$ & 0.685 & 0.99 & $0.93-1.06$ & 0.785 \\
\hline SLS with eyes open (sec) & $74.89(62.11)$ & $59.57[14.32-121.01]$ & $60.74(57.02)$ & $36.95[14.12-105.73]$ & $70.52(60.67)$ & 0.267 & 1.00 & $0.99-1.00$ & 0.331 \\
\hline Stepping test (times/20 sec) & $32.41(4.48)$ & & $29.94(4.77)$ & & $31.65(4.69)$ & $0.011^{*}$ & 0.89 & $0.81-0.98$ & $0.018^{* * *}$ \\
\hline Grip strength (kg) & $23.90(3.41)$ & & $23.13(4.28)$ & & 23.66 (3.69) & 0.323 & 0.95 & $0.85-1.07$ & 0.395 \\
\hline
\end{tabular}

(1) $p$-value by $t$-test or Mann-Whitney $U$ test ${ }^{(2)}$ Adjusted for age

${ }^{*} p<0.05$ on the $t$-test

${ }^{* *} p<0.05$ on the Mann-Whitney $U$ test

*** $p<0.05$ on the logistic regression

Age, ODK/pa/, /ta/, /ka/, and SLS were tested by the Mann-Whitney $U$ test.

$\mathrm{Cl}$ : confidence interval, IQR: interquartile range, ODK: oral diadochokinesis, OR: odds ratio, SD: standard deviation, SLS: single-leg stance

ences affect motor function in older adults. The strength of the cerebellum's functional connectivity with the premotor cortex has been reported to be associated with masticatory performance [20]; therefore, we selected measurement items considered to involve the cerebellum as indicators of motor control. Syllable repetition tasks, such as ODK, which are used to assess tongue and lip motor skills, have proven to be particularly sensitive to cerebellar involvement [27]. Balance has been reported to involve the cerebellum, basal ganglia, and thalamus in several studies [28]. For agility, the cerebellum is also said to control the timing of contraction of various muscles to ensure the speed and accuracy of movements [29]. Of these, tongue and lip motor skills and physical agility have been significantly associated with masticatory movement. The association of motor function in separate parts of the body, the oral region and lower limbs, suggests that these results might be due to central rather than peripheral influences. In contrast, SLS, used as an indicator of balance, did not show a significant association with masticatory movement. SLS, also referred to as one-leg stance (OLS) or the one-legged stance test (OLST), has often been used as a clinical balance test to assess postural steadiness in older people [36]. However, recent studies have reported that SLS is not only influenced by postural adjustment, but also by muscle strength $[37,38]$. Tongue pressure or grip strength, used as indicators of muscle strength in the present study, did not show a significant association with masticatory movement. It could be inferred that there was no significant association because of the stronger influence of muscle strength over that of balance in SLS.

The present study revealed that some people have abnormal masticatory movement even after excluding people with various peripheral and disease-associated factors. In addition, the abnormality was associated with other oral and body motor functions, suggesting that the abnormality may be due to central motor control. The results showed the importance of motor function assessment when seeking factors associated with masticatory disorders in older people. In clinical practice, motor function assessment enables us to consider methods including various exercises "to optimize masticatory performance in dental prosthesis users" [39], which may improve the treatment effect. For example, masticatory performance has been reported to improve with interventions of lip, tongue, cheek stretching, and masticatory muscle exercises in patients whose occlusion has been restored by prosthetic treatment [40]. Thus, comprehensive assessment and treatment focusing on motor function, in addition to morphology and restoration of defects, could provide dental treatment more suited to the needs of patients.

The first limitation of this study was sampling bias. The subjects of this study were independent older people living in the community, especially those who were physically fit enough to participate in physical fitness assessment sessions and complete multiple measures. Therefore, the data obtained in this study should be interpreted with caution. Furthermore, as only women were included in the study, further investigation of sex differences is required.

The second limitation was the device used. Some devices for measuring mandibular movement provide more detailed assessment, such as the K7 Evaluation System [14]. Further research on the speed of jaw open-close movement and masticatory muscle activity using such instruments is needed. However, in the present study, the use of a major clinical device showed the possibility that the results could be applied to daily clinical practice.

The advantage of the present study was that we recruited over 100 older women with clinically normal occlusion without missing teeth. Thus, it was meaningful to be able to examine the motor function of older people by eliminating disease and organic factors as much as possible.

\section{Conclusion}

The present study suggests that masticatory movement in older women is associated with masticatory performance, tongue and lip motor skills, and physical agility, all of which may be influenced by central motor control. 


\section{Acknowledgements}

This research was performed without any special funding.

\section{Conflicts of interest}

The authors declare no conflict of interest.

\section{References}

[1] Hatch JP, Shinkai RS, Sakai S, Rugh JD, Paunovich ED. Determinants of masticatory performance in dentate adults. Arch.OralBiol. 2001;46:641-8. https:// doi.org/10.1016/s0003-9969(01)00023-1, PMID:11369319

[2] Ikebe K, Matsuda K, Kagawa R, Enoki, K, Yoshida M, Maeda Y, et al. Association of masticatory performance with age, gender, number of teeth, occlusal force and salivary flow in Japanese older adults : is ageing a risk factor for masticatory dysfunction? Arch.OralBiol. 2011;56:991-6. https://doi. org/10.1016/j.archoralbio.2011.03.019, PMID:21529776

[3] Minakuchi S, Tsuga K, Ikebe K, Ueda T, Tamura F, Nagao K, et al. Oral hypofunction in the older population: Position paper of the Japanese Society of Gerodontology in 2016 Gerodontology. 2018;35:317-24. https:// doi.org/10.1111/ger.12347, PMID:29882364

[4] Fukutomi E, Kimura Y, Wada T, Okumiya K, Matsubayashi K. Long-term care prevention project in Japan Lancet. 2013;381:116. https://doi.org/10.1016/ s0140-6736(13)60049-5, PMID:23312754

[5] Yoshida M, Kikutani T, Okada G, Kawamura T, Kimura M, Akagawa Y. The effect of tooth loss on body balance control among community-dwelling elderly persons. Int J Prosthodont. 2009;22:136-9. PMID:19418857

[6] Yoshida M, Kanehisa Y, Ozaki Y, Iwasa Y, Fukuizumi T, Kikutani T. One-leg standing time with eyes open: comparison between the mouth-opened and mouth-closed conditions. Cranio. 2015;33:15-8. https://doi.org/10.1179/ 2151090314y.0000000007, PMID:25547139

[7] Yamaga T, Yoshihara A, Ando Y, Yoshitake Y, Kimura Y, Shimada M, et al. Relationship between dental occlusion and physical fitness in an elderly population. J Gerontol A Biol Sci Med Sci 2002;57:M616-20. https:// doi.org/10.1093/gerona/57.9.m616, PMID:12196501

[8] Sakai K, Nakayama E, Tohara H, Maeda T, Sugimoto M, Takehisa T, et al. Tongue Strength is Associated with Grip Strength and Nutritional Status in Older Adult Inpatients of a Rehabilitation Hospital. Dysphagia. 2017;32:2419. https://doi.org/10.1007/s00455-016-9751-5, PMID:27687521

[9] linuma T, Arai Y, Fukumoto $M$, et al. Maximum occlusal force and physical performance in the oldest old: the Tokyo oldest old survey on total health. J Am Geriatr Soc. 2012;60:68-76. https://doi.org/10.1111/j.1532-5415. 2011.03780.x, PMID:22211666

[10] Hirao A, Murata S, Murata J, Kubo A, Hachiya M, Asami T. Relationships between the Occlusal Force and Physical/Cognitive Functions of Elderly Females Living in the Community. J Phys Ther Sci. 2014;26:1279-82. https:// doi.org/10.1589/jpts.26.1279, PMID:25202197

[11] Izuno H, Hori K, Sawada M, Fukuda M, Hatayama C, Ito K, et al. Physical fitness and oral function in community-dwelling older people: a pilot study. Gerodontology. 2016;33:470-9. https://doi.org/10.1111/ger.12186, PMID:25664778

[12] Samulski B, Prebor J, Armitano C, Morrison S. Coupling of motor oscillators - What really happens when you chew gum and walk? Neurosci Lett. 2019;698:90-6. https://doi.org/10.1016/j.neulet.2019.01.016, PMID:30634010

[13] Pröschel P, Hofmann M. Frontal chewing patterns of the incisor point and their dependence on resistance of food and type of occlusion J Prosthet Dent. 1988;59:617-24. https://doi.org/10.1016/0022-3913(88)90082-0, PMID:3164394

[14] Piancino MG, Comino E, Talpone F, Vallelonga T, Frongia G, Bracco P. Reverse-sequencing chewing patterns evaluation in anterior versus posterior unilateral crossbite patients Eur J Orthod. 2012;34:536-41. https://doi. org/10.1093/ejo/cjr109, PMID:21921301

[15] Kobayashi Y, Shiga H, Arakawa I, Yokoyama M, Nakajima K. Masticatory path pattern during mastication of chewing gum with regard to gender difference. J Prosthodont Res. 2009;53:11-4. https://doi.org/10.1016/j.jpor. 2008.08.002, PMID:19318065

[16] Trulsson M, Johansson RS. Encoding of tooth loads by human periodontal afferents and their role in jaw motor control. Prog Neurobiol. 1996;49:26784. https://doi.org/10.1016/s0301-0082(96)00016-0, PMID:8878305
[17] Watanabe A, Shiga H, Kobayashi Y. Occlusal Contacting Condition and Masticatory Function of 2 Types of Pattern That Differ in the Closing Path of the Mandibular Incisal Point During Chewing J Prosthodont Res. 2011;55:243-7. https://doi.org/10.1016/j.jpor.2011.03.004, PMID:21531190

[18] Kuramochi A, Shiga H. Effect of Denture Treatment on Masticatory Movement in Patients With Complete Dentures J Prosthodont Res. 2019;63:2459. https://doi.org/10.1016/j.jpor.2018.12.005, PMID:30692048

[19] Morquette P, Lavoie R, Fhima MD, Lamoureux X, Verdier D, Kolta A. Generation of the masticatory central pattern and its modulation by sensory feedback. Prog Neurobiol. 2012;96:340-55. https://doi.org/10.1016/j.pneurobio. 2012.01.011, PMID:22342735

[20] Lin CS, Wu SY, Wu CY, Ko HW. Gray Matter Volume and Resting-State Functional Connectivity of the Motor Cortex-Cerebellum Network Reflect the Individual Variation in Masticatory Performance in Healthy Elderly People. Front Aging Neurosci. 2015;7:247. https://doi.org/10.3389/fnagi.2015.00247, PMID:26779015

[21] Andersen BB, Gundersen HJ, Pakkenberg B. Aging of the Human Cerebellum: A Stereological Study J Comp Neurol. 2003;466:356-65. https://doi. org/10.1002/cne.10884, PMID:14556293

[22] Bernard JA, Seidler RD. Moving forward: age effects on the cerebellum underlie cognitive and motor declines. Neurosci Biobehav Rev. 2014;42:193207. https://doi.org/10.1016/j.neubiorev.2014.02.011, PMID:24594194

[23] Miller, S.C. Textbook of Peridontia. 3rd ed. Philadelphia: The Blaskiston Co; 1950.

[24] Cooper R, Hardy R, Sayer AA, Ben-Shlomo Y, Birnie K, Cooper C, et al. Age and gender differences in physical capability levels from mid-life onwards: the harmonisation and meta-analysis of data from eight UK cohort studies PLoS One. 2011;6:e27899. https://doi.org/10.1371/journal.pone.0027899, PMID:22114723

[25] Barbosa AR, Souza JMP, Lebrão ML, Laurenti R, Marucci MFN. Functional limitations of Brazilian elderly by age and gender differences: data from SABE Survey Cad Saude Publica. 2005;21:1177-85. https://doi.org/10.1590/ s0102-311x2005000400020, PMID:16021255

[26] Faul F, Erdfelder E, Lang AG, Buchner A. G*Power 3: a flexible statistical power analysis program for the social, behavioral, and biomedical sciences. Behav Res Methods. 2007;39:175-91. https://doi.org/10.3758/bf03193146, PMID:17695343

[27] Mariën P, Ackermann H, Adamaszek M, Barwood CHS, Beaton A, Desmond J, et al. Consensus Paper: Language and the Cerebellum: an Ongoing Enigma Cerebellum. 2014;13:386-410. https://doi.org/10.1007/s12311-0130540-5, PMID:24318484

[28] Surgent OJ, Dadalko OI, Pickett KA, Travers BG. Balance and the Brain: A Review of Structural Brain Correlates of Postural Balance and Balance Training in Humans Gait Posture. 2019;71:245-52. https://doi.org/10.1016/j. gaitpost.2019.05.011, PMID:31082657

[29] Wickelgren I. The Cerebellum: The Brain's Engine of Agility Science. 1998; 281:1588-90. https://doi.org/10.1126/science.281.5383.1588, PMID:9767021

[30] Kimura M, Mizuta C, Yamada Y, Okayama Y, Nakamura E. Constructing an Index of Physical Fitness Age for Japanese Elderly Based on 7-year Longitudinal Data: Sex Differences in Estimated Physical Fitness Age Age (Dordr). 2012;34:203-14. https://doi.org/10.1007/s11357-011-9225-5, PMID:21424789

[31] Shiga H, Ishikawa A, Nakajima K, Tanaka A. Relationship between masticatory performance using a gummy jelly and food intake ability in Japanese complete denture wearers. Odontology. 2015;103:356-9. https://doi.org/ 10.1007/s10266-014-0170-5, PMID:25183492

[32] Sakayori T, Maki Y, Hirata S, Okada M, Ishii T. Evaluation of a Japanese "prevention of long-term care" project for the improvement in oral function in the high-risk elderly. Geriatr Gerontol Int. 2013;13:451-7. https://doi. org/10.1111/j.1447-0594.2012.00930.x, PMID:22963330

[33] Hayashi R, Tsuga K, Hosokawa R, Yoshida M, Sato Y, Akagawa Y. A novel handy probe for tongue pressure measurement. Int J Prosthodont. 2002;15:385-8. PMID:12170854

[34] Rosano C, Aizenstein HJ, Studenski S, Newman AB. A regions-of-interest volumetric analysis of mobility limitations in community-dwelling older adults. J Gerontol A Biol Sci Med Sci. 2007;62:1048-55. https://doi.org/ 10.1093/gerona/62.9.1048, PMID:17895446

[35] Bernard JA, Peltier SJ, Wiggins JL, Jaeggi SM, Buschkuehl M, Fling BW, et al. Disrupted cortico-cerebellar connectivity in older adults. Neuroimage. 2013;83:103-19. https://doi.org/10.1016/j.neuroimage.2013.06.042, PMID:23792980

[36] Berg KO, Wood-Dauphinee SL, Williams Jl, Maki B. Measuring balance in the elderly: validation of an instrument Can J Public Health. 1992;83:S7-11. PMID:1468055 
[37] Iverson BD, Gossman MR, Shaddeau SA, and Turner Jr, ME. Balance performance, force production, and activity levels in noninstitutionalized men 60 to 90 years of age Phys Ther. 1990;70:348-55. https://doi.org/10.1093/ ptj/70.6.348, PMID:2345778

[38] Jonsson E, Seiger A, and Hirschfeld H One-leg stance in healthy young and elderly adults: a measure of postural steadiness? Clin Biomech. 2004;19:68894. https://doi.org/10.1016/j.clinbiomech.2004.04.002, PMID:15288454
[39] Kumar A, Kothari M, Grigoriadis A, Trulsson M, Svensson P. Bite or brain: Implication of sensorimotor regulation and neuroplasticity in oral rehabilitation procedures J Oral Rehabil. 2018;45:323-33. https://doi.org/10.1111/ joor.12603, PMID:29314189

[40] Kim HJ, Lee JY, Lee ES, Jung HJ, Ahn HJ, and Kim BI. Improvements in oral functions of elderly after simple oral exercise Clin Interv Aging. 2019;14:91524. https://doi.org/10.2147/cia.s205236, PMID:31190777

This is an open-access article distributed under the terms of Creative Commons Attribution-NonCommercial License 4.0 (CC BYNC 4.0), which allows users to distribute and copy the material in any format as long as credit is given to the Japan Prosthodontic Society. It should be noted however, that the material cannot be used for commercial purposes. 